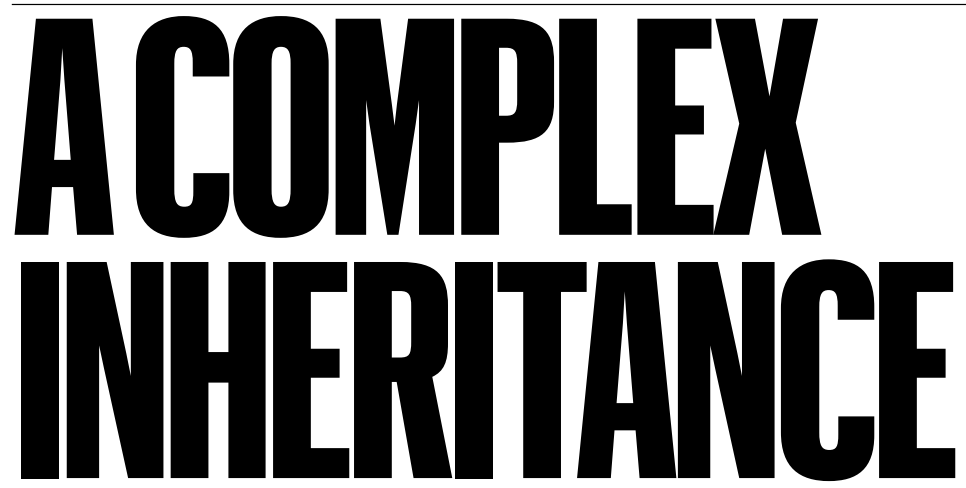

Researchers are finding links between people's genes and complex attributes such as how they vote or the time spent in school. The worry is that their results will be misconstrued. By David Adam

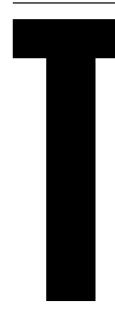

he deep coal mine at the Yorkshire village of Kellingley closed in 2015 - the last of more than 1,000 such pits that once drove British industry. As the mines closed, the jobs went with them. Faced with economic and social decline, many people who could moved away.

Geneticist Abdel Abdellaoui has never been to Kellingley or any of the United Kingdom's other former coal-mining regions. But he has found something surprising about the towns and their inhabitants. His research shows that the DNA in these districts is flecked with disadvantage ${ }^{1}$, just as the coal seams once threaded through the ground.

By looking at the genomes of people living in former coal-mining areas, he has found genetic signatures associated with spending fewer years at school compared with people outside those areas, and - at weaker significance levels - variants that correlate with lower socio-economic status. Somegenetic variants even correlate with political persuasion and whether or not communities voted to leave the European Union in the 2016 Brexit referendum.

Abdellaoui, who works at the University of Amsterdam in the Netherlands, acknowledges that he is venturing onto politically charged ground. "I try to understand human genetic variation and this is what I run into," he says.

The study ${ }^{1}$ - published this week in Nature Human Behaviour - is a high-profile example of an emerging trend: using huge amounts of data and computing power to uncover genetic contributions to complex social traits. Studies published in the past decade have examined genetic variants linked to aggression, same-sex sexual behaviour, well-being and antisocial behaviours, as well as the tendency to drink and smoke. In doing such science, geneticists are heading for controversial territory. They have even been accused of "opening a new door to eugenics", according to the title of a 2018 MIT Technology Review article by science historian Nathaniel Comfort ${ }^{2}$.

To the geneticists and social scientists doing this work, the results offer a useful and important guide to the relative contributions of nature and nurture to specific behavioural traits - just as genetic analysis can already highlight people who have an increased risk of cancer or heart disease. The approach could, for example, improve understanding of how the environment affects complex traits, and so offer a way to intervene to improve areas such as public education.

"It is super-exciting," says Philipp Koellinger, a genoeconomist at Vrije University Amsterdam in the Netherlands. "It gives us better and more-precise ways for scientists to answer questions they

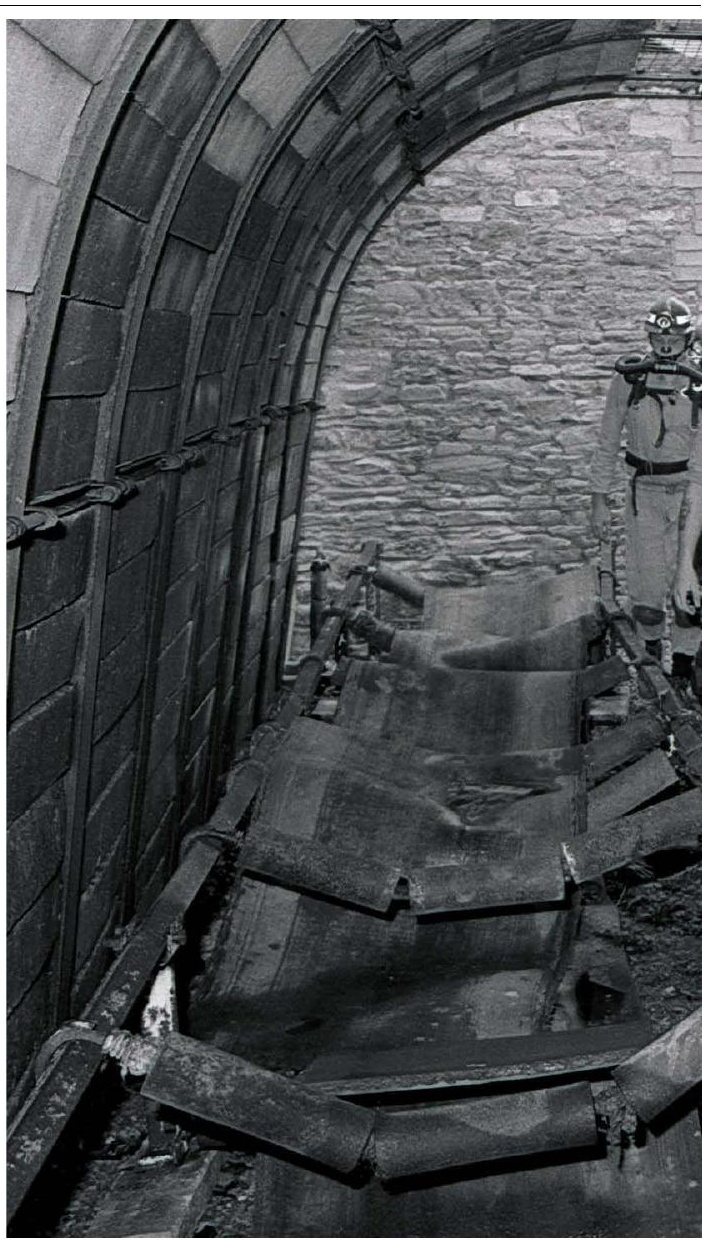

have been interested in for a long time."

Caveats abound. The genetic contribution to any behavioural trait is relatively small and easily swamped by the influence of the environment. The studies can reveal only whether someone is likely to have a certain trait, and cannot predict the qualities of any one individual. Most scientists are quick to point out why they do this work - to establish what role, if any, genetics has in behaviour - and to lay out its limitations.

But not everyone is listening: already, some companies see a market in reading DNA like a fortune-teller reads tea leaves. "That stuff totally gives me the shivers. But it's happening," Koellinger says.

Critics charge that the ethical and societal risks of acting on such information are too great. "One of the main concerns is not so much the study of genomics, but how are we going to use it," says Maya Sabatello, a bioethicist at Columbia University in New York City. “Who's going to benefit? Who's not going to benefit? We live in a very unequal society and this is a major challenge."

\section{Strength in numbers}

For decades, geneticists assumed that most traits were governed by just a handful of genes - whether it was a relatively simple one such as height, or something as complex as antisocial behaviour. But as the sample sizes swelled, 


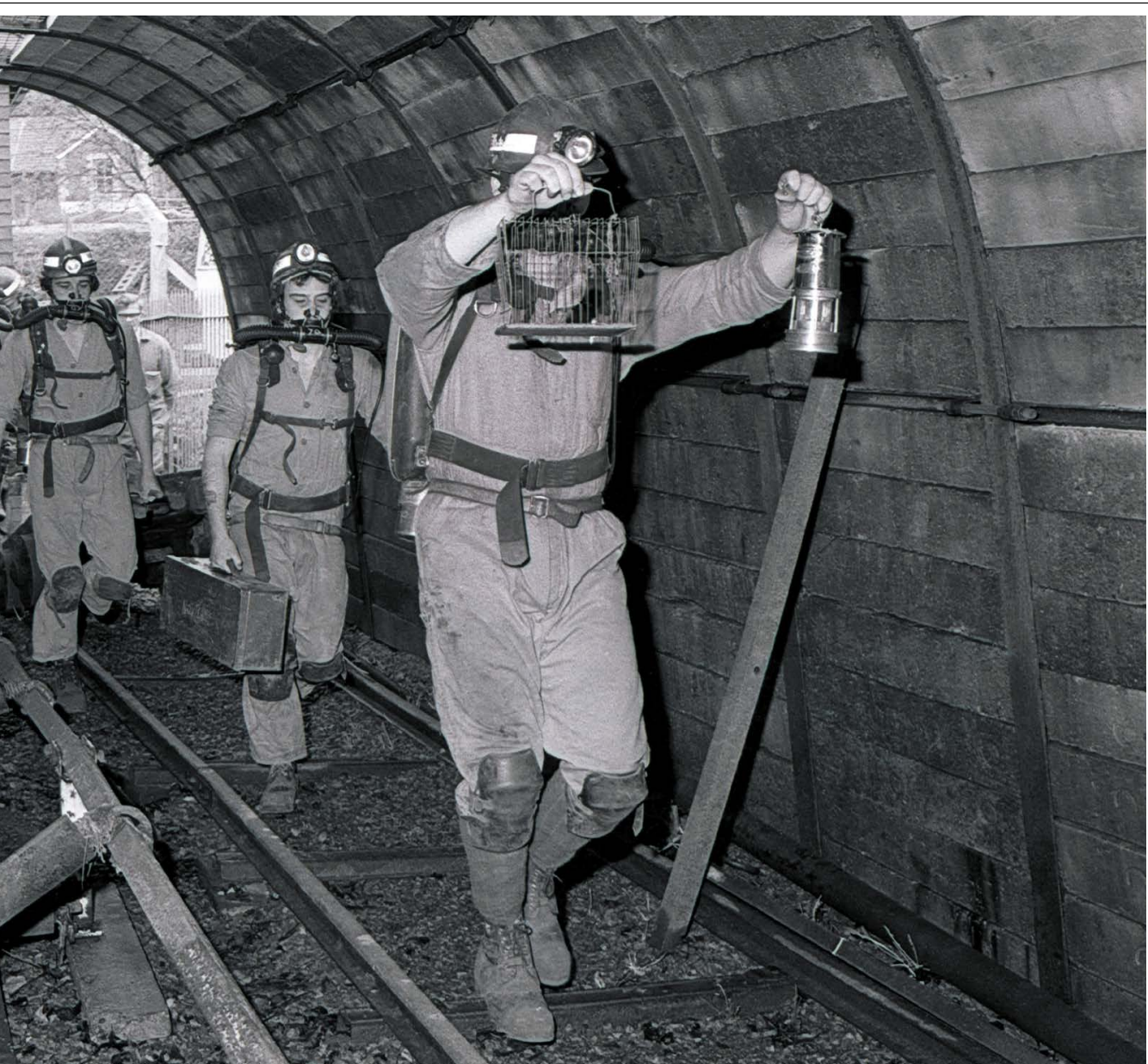

In former UK coal mining areas, genetic variants are linked with spending less time in school.

researchers began to find hundreds of variants that each have a relatively small effect on a trait. These projects - known as genome-wide association studies (GWAS) - build up a picture of which DNA letters vary from person to person (called single nucleotide polymorphisms, or SNPs), which variants are most common in people with a given trait and how much of the difference between individuals these SNP patterns represent.

Adding up the contributions made by all these spots on the genome gives researchers a measure of the importance of genetics to a trait, known as a polygenic score. For height, which is known to have a strong genetic influence, GWAS show that variants can together account for $20 \%$ of the variation.

As studies into physiology and disease piled up, scientists began to wonder whether the methods would work on social and psychological attributes.

For some complex traits, such as social isolation, researchers have found only a weak influence; one study ${ }^{3}$ noted that heritability for that trait hovers at $4 \%$. But for others, the signal from genetics studies has blossomed from initially feeble to surprisingly strong. In 2013, a large group of researchers working under the umbrella name The Social Science Genetic Association Consortium (SSGAC) reported the first GWAS of educational attainment ${ }^{4}$, defined as years of schooling. The study found three SNPs that together could explain a meagre $2 \%$ of the variation in years of education. But then, a 2016 repeat by the same consortium using a sample that included almost 300,000 peoplemore than double the number in the 2013 study - found 74 SNPs that could explain 3.2\% of the variation ${ }^{5}$. When the consortium combined data from 1.1 million people, they discovered more than 1,200 SNPs that together accounted for $11-13 \%$ of the variation ${ }^{6}$. That means the genes for educational attainment can explain about as much variation in a child's time in education as their family's socio-economic status can. "I think that's really quite remarkable," says Tim Morris, an epidemiologist at the University of Bristol, UK.

Beyond education, researchers have examined other socially shaped traits. In 2016, for instance, the SSGAC published a GWAS of almost 300,000 people and identified 3 SNPs associated with self-reported measures of well-being ${ }^{7}$. And in 2017, a weak genetic signature for antisocial behaviour showed up in a GWAS of a group of 6,200 Finnish prisoners ${ }^{8}$. Neither study produced a polygenic score, but researchers expect scores for these traits will emerge as sample sizes continue to grow.

The growing power of GWAS inspired
Abdellaoui to ask a different question: how do social traits such as educational attainment vary across a country? To find out, he and his team dug into the UK Biobank data set, which holds blood and tissue samples and survey responses for almost 450,000 people and cross-references the information to medical data such as hospital admissions.

The team looked at previous studies to amass a list of 33 health and behavioural traits and the genetic variants that influence them, adding up the contribution of each variant to get a polygenic score. The researchers then investigated the UK Biobank samples to see whether these genotypes differed across the United Kingdom. They first discounted genetic variation caused by historical regional differences in ancestry, throwing out variants that are common because of shared ancestry rather than because they govern a trait. Then they could see which traits still clustered into certain regions. For some traits - caffeine consumption, for example - there was no regional difference. But for others, such as educational attainment, the difference was significant. The researchers found that people living in former coal-mining regions had, on average, fewer genetic variants that correlated with staying in school longer or with going on to higher education ${ }^{1}$.

Peter Visscher, a geneticist at the University of Queensland in Australia who worked on the study, says it's not clear what underlying biology the genetic patterns identified represent. "I see that as a proxy for genes to do with intelligence and maybe perseverance, and maybe a bit of risk-taking."

Abdellaoui stresses that what they have produced is more description than explanation. "There are a whole bunch of variables that are clustering in the lower economic areas, but it's very difficult to say anything about directions of causality."

The researchers think the regional difference is down to the migration of more-educated people to richer areas that offer them jobs, leaving behind people who have genetic signatures linked to spending less time in school. This social stratification could become more marked over time, they say. "If that goes on for multiple generations, then for the sort of social inequalities already there, you run the risk of increasing those inequalities on a biological level," says Abdellaoui.

The researchers found the same geographic pattern for other traits, but the relationships were weaker. Genotypes known to be strongly associated with lower socio-economic status and lower cognitive ability were found more often in the poorer areas. These genotypes, the scientists reported, were associated with people's political views. Those in coal-mining areas had more genetic variants linked to lower socio-economic status, and were also more likely to vote for the left-wing Labour party or the right-wing UK Independence Party. 
Individuals were also more likely to have voted for the United Kingdom to leave the EU in the Brexit referendum. Abdellaoui says this does not mean that someone is genetically predisposed to vote in a certain way.

Other researchers in the field agree with this caution. "Overall I like the paper and think that they've done a good job with it," says Morris. "My main fear is that these results will be over-interpreted. They are informative descriptive statistics, but descriptive nonetheless." He also notes the UK Biobank data are "extremely selective" and not likely to fully represent the populations of the former coal-mining regions. "For the regional results, these really must be interpreted with care."

The results of this kind of study are based on associations, and must be presented very carefully to prevent suggestions that a person's genes determine their outcomes, says Daniel Benjamin, a behavioural economist at the University of Southern California in Los Angeles. He is wary of comparisons between his field and the spectre of eugenics, an idea from the beginning of the twentieth century that people seen as having 'inferior' genes should be prevented from having children. "Those of us who do work in this area have an ethical obligation, and that ethical obligation is even stronger in the case of the genetics of behaviour because of past terrible misinterpretations and horrible consequences," he says.

One of the biggest sources of confusion is what a polygenic score actually shows about the contributions of nature and nurture, Benjamin says. "People have a really hard time understanding that genes don't determine behaviour."

Abdellaoui says of his UK study: "We are in no way suggesting the genes are the sole determinant of someone's educational outcome. It's a combination of environmental and genetic effects."

\section{Genetics in the classroom}

Another disclaimer is that polygenic scores represent the 'risk' of having a particular trait, and don't necessarily suggest that genetics is a major factor in behaviour. For instance, the scores cannot foretell that one individual will definitely graduate from university and another will quit school aged 16. “I don't think that polygenic scores are at the level of predictive ability that would allow you to make those kinds of individual judgements with any degree of certainty," says Paige Harden, a psychologist at the University of Texas at Austin.

When Benjamin and his team put together the most recent GWAS on education ${ }^{6}$, his team released an accompanying 20-page list of frequently asked questions to explain the study's motives, which made clear that the scientists thought there were no implications for education policy. Not everyone is so cautious, says Morris. "There are quite a few academic papers coming out that can't resist a final sentence right at the end, along the lines of 'the DNA revolution is coming and genes will soon be useful for predicting education', which I think is quite irresponsible," he says. He wants such papers to include more context - for example, pointing out that existing information such as a student's previous attainment can already do a better job of predicting their future performance than a polygenic score can.

A working group announced earlier this month by bioethics think tank The Hastings Center in Garrison, New York, plans to examine the field and advise researchers and stakeholders on how to conduct and talk about the work (see go.nature.com/2vtbpey).

But others are less guarded. They argue that genetic screens of behaviour and cognitive

\section{"Many teachers are worried that trying to use genetics as a tool in education could potentially be misused."}

ability could help children as young as three to fare better at school. "It can't be right for education to continue to ignore genetic influence, because it's far and away the most important source of individual differences," says Robert Plomin, a psychologist at King's College London, who is one of the more bullish voices in the debate and whose interpretations of the studies are controversial.

Sabatello, the bioethicist, predicts that the first applications will be in specialist education, such as for cases in which the parents of children with conditions such as attention deficit hyperactivity disorder (ADHD), autism spectrum disorder or dyslexia could use genotypes as evidence to demand a different approach for their child. "Parents want the genomic information to persuade authorities or educational entities that their kids need the specialist intervention."

At the moment, there are no reliable polygenic scores to assess the contribution of genes to these conditions, but large-scale studies, more powerful than those done before, including a major GWAS currently under way for ADHD, could produce them in the future.

Although the focus on identifying and helping children with extra educational needs might sound altruistic, it, too, has a troubling historical precedent. Intelligence tests, which were first developed at the beginning of the twentieth century to pick out children who could benefit from extra attention, quickly became used to reinforce discrimination against minority populations or institutionalize children deemed to be 'feeble-minded'.

"Many teachers are worried that trying to use genetics as a tool in education could potentially be misused to validate race and class-based differences," says Daphne Martschenko, who has just finished a PhD at the University of Cambridge, UK, that investigated attitudes in education to genetics.

In fact, because GWAS are done mostly using data from people of European ancestry, this could make the results less applicable for different ethnic groups. "A real pragmatic challenge is that we don't have good genetic indicators for children of colour," Harden says.

Morris thinks that this could compound existing inequality in education. "If you can't do something for everyone in the system, then you can't do it."

\section{Responsible research}

Many in the field agree that the most useful application of these results will be to allow better-quality research into environmental - not genetic - influences on complex behavioural traits, by taking out the influence of genetics while studying some other factor. "It's an unsexy thing to talk about," says Harden, "but a better idea is using genetics as a control variable to work out what actually works to improve learning."

Researchers could include children with similar polygenic scores in both the control and test groups when trialling an intervention, for instance.

The results could also help scientists to probe whether the effects of genetics depend on an individual's environment - whether certain gene variants kick in only under some circumstances. And more-sophisticated genetic studies could unpick the importance of something called genetic nurture, in which environmental influences are misidentified as genetic. This could be the case with education, because well-educated parents both pass on their genes and are more likely to contribute indirectly by encouraging their children's schooling?.

The priority for most researchers in this field is to do more and bigger studies, to produce ever-stronger signals and tackle different traits such as income and social withdrawal. Meanwhile, those at the educational coalface don't need insight from genetics to improve outcomes, says Sabatello. “We need to look at the environment. Children who are hungry can't study. We don't need to have their genes for that."

David Adam is a freelance journalist based near London.

\footnotetext{
1. Abdellaoui, A. et al. Nature Hum. Behav. https://doi. org/10.1038/s41562-019-0757-5 (2019).

2. Comfort, N. 'Sociogenomics is opening a new door to eugenics' MIT Technol. Rev. (23 October 2018).

3. Day, F. R., Ong, K. K. \& Perry, J. R. B. Nature Commun. 9, 2457 (2018).

4. Rietveld, C. A. et al. Science 340, 1467-1471 (2013). 5. Okbay, A. et al. Nature 533, 539-542 (2016).

6. Lee, J. J. et al. Nature Genet. 50, 1112-1121 (2018).

7. Okbay, A. et al. Nature Genet. 48, 624-633 (2016).

8. Tielbeek, J. J. et al. JAMA Psychiatry 74, 1242-1250 (2017).

9. Kong, A. et al. Science 359, 424-428 (2018).
} 